\title{
The fundamentals of epidemiology and ethics in science
}

\author{
Hyogo Horiguchi ${ }^{1}$
}

Received: 24 November 2015/Published online: 14 December 2015

(C) The Japanese Society for Hygiene 2015

\section{Dear Editor,}

I appreciate the response to my comments on the article by Ilmiawati et al. [1] published in Environ Health Prev Med from the author. However, it was not convincing in terms of the fundamentals of epidemiology and ethics in science.

Again, epidemiology is essentially a comparative discipline, requiring the study of different places or different groups of people [2]. This is one of the fundamental concepts and procedures of epidemiology, and the author seems to understand this. To verify "the hypothesis that children in Asahikawa may eat less marine food, and different types of fish from ones in other areas in Japan", it is, as a matter of course, necessary to investigate other areas in Japan and present evidence for it. In addition, the data in this study were compared with those of a national representative of US children from NHANES or other developed countries, meaning that the author considered the children from Asahikawa City as representative of Japan, as "no Japanese representativeness can be delineated without comparing other nationality".

The author insisted that the interference of the high level of urinary molybdenum with the measurement of urinary cadmium by inductively coupled plasma mass spectrometry (ICP-MS) is negligible, but it is contradictory to what the author himself reported previously [3]. According to the report, it is necessary to adjust the urinary cadmium concentrations measured by ICP-MS, since the level of the interference can be as high as $20 \%$ [3]. A more serious problem is that the paper was published (in 2015) after the report (in 2012), indicating that the author used unadjusted, inaccurate data on the urinary cadmium concentration for publication while knowing the necessity of adjustment, even though he and IDEA were unaware of the phenomena at the time of this study (in 2008 and 2009). It is clearly against ethics in science.

\section{References}

1. Ilmiawati C, Yoshida T, Itoh T, Nakagi Y, Saijo Y, Sugioka Y, Sakamoto M, Ikegami A, Ogawa M, Kayama F. Biomonitoring of mercury, cadmium, and lead exposure in Japanese children: a cross-sectional study. Environ Health Prev Med. 2015;20:18-27.

2. Lilienfeld DE, Stolley PD. Laying the foundations: the epidemiologic approach to disease. In: Foundations of epidemiology, 3rd edn. New York: Oxford University Press; 1994. pp. 3-21.

3. Kayama F. (2012) Combined exposure of arsenic and lead and its health effects among farmers exposed to cadmium through consumption of self-harvested rice. Report of Health and Labor Sciences Research. http://www.mhlw-grants.niph.go.jp/niph/search/ NIDD02.do?resrchNum=201234011B. Accessed 1 Sept 2015.

This reply refers to the article available at doi:10.1007/s12199-0150461-7.

Hyogo Horiguchi

hhyogo@med.kitasato-u.ac.jp

1 Department of Hygiene, Kitasato University School of Medicine, 1-15-1 Kitasato, Minami-ku, Sagamihara, Kanagawa 252-0374, Japan 